\title{
The Representation of Migration in the Hungarian Context
}

\author{
Éva Illés $a *$ (iD \\ a Eötvös Loránd University, 5 Rákóczi út, Budapest, 1088, Hungary
}

Received 09 November 2018 | Received in revised form 18 June 2019 | Accepted 04 July 2019

\author{
APA Citation: \\ Illés, É. (2019). The representation of migration in the Hungarian context. Eurasian Journal of Applied Linguistics, \\ 5(2), 203-218. Doi: 10.32601/ejal.599263
}

\begin{abstract}
Despite the decreasing number of immigrants and their negligible presence, migration has dominated Hungarian public discourse. The article investigates issues related to migration in three contexts. First, samples from the government's immigration discourse, including a legislative package proposal and billboards, are subjected to critical discourse analysis to establish what terminology and rhetorical devices are used to evoke particular kinds of emotion in the readers. Second, the billboards of a countercampaign organised by a Hungarian joke political party are explored to examine how they managed to turn around the message of the official campaign. Third, the paper investigates whether state education in Hungary can establish the golden mean and provide a balanced view of migration. For exploring the latter question, documents, such as the Hungarian National Core Curriculum in general and the section on the teaching of foreign languages in particular are analysed. The findings of the analyses show inconsistencies in the use of the relevant terminology and a predominantly biased view of migration in Hungary.

(C) 2019 EJAL \& the Authors. Published by Eurasian Journal of Applied Linguistics (EJAL). This is an open-access article distributed under the terms and conditions of the Creative Commons Attribution license (CC BY-NC-ND) (http://creativecommons.org/licenses/by-nc-nd/4.0/).
\end{abstract}

Keywords: anti-immigration campaign; political discourse; terminology; national curriculum

\section{Introduction}

Hungary presents a paradox when it comes to the issue of migration. This is due to the fact that while the number of migrants fleeing from their homeland and allowed to settle down in Hungary is negligible, the theme of migration has been dominating public discourse for a number of years. For example, of the 312 Facebook posts by the Hungarian Prime Minister in 2018 (up to 20 December), 38 (12\%) were concerned with migration (https://index.hu/belfold/2018/12/27/orban_facebook_influenszer_gasztroblogger/). The issue of migration has seeped into everyday life in other ways too. In a wall calendar

\footnotetext{
* Corresponding author.

E-mail address: illes.eva@btk.elte.hu
} 
published by a local authority in the capital of Hungary, a special section has been devoted to the details of police officers with whom people living in that particular area can get in touch in case of emergency or when witnessing a crime. On the list of crimes, the first one mentioned is drug abuse, while the second is migration and illegal immigration (https://444.hu/2018/12/18/a-2019-es-jozsefvarosi-naptarbolmegtudhatod-kit-kell-ertesitened-ha-zavaro-bevandorlo-vagy-hajlektalan-van-akornyeken). There have also been measures at the legislative level. In 2018, the Government proposed a legislative package called Stop Soros, which was passed by Parliament in June 2018. The aim was "to protect Hungary from immigration and its organisers" (http://www.kormany.hu/en/prime-minister-s-office/news/government-tosubmit-tightened-stop-soros-legislative-package-on-tuesday).

Migration has remained high on the agenda despite a sharp decline in the number of immigrants arriving in Hungary over the past few years. After the 2015 peak, 2016 and 2017 saw a considerable decrease in the number of arrivals: from 177,135 in 2015 to 29,432 in 2016 and 3,397 in 2017 (KSH Hungarian Central Statistical Office, n. d.).

The drop in numbers was caused by amendments to asylum legislation affecting arrival procedures and the treatment of asylum seekers. In addition,

in August and September 2015, together with the completion of the fence, Hungary designated Serbia as a safe third country, allowed for expedited asylum determination, and limited procedural safeguards. Additionally, climbing through the border fence or damaging it became a criminal offence punishable with imprisonment." (International Organization for Migration)

It should be noted, however, that the 2015 wave of immigration was not the first in the recent history of Hungary. A significant flow of immigration in the 1990s was followed by another one in 2008. In the 1990 s, more than $70 \%$ of immigrants came from neighbouring countries with Hungarian populations, such as Romania, Ukraine and former Yugoslavia. From 2008, the ratio of immigrants from these countries started to decrease and by 2011 it went down to 33\% (Gödri, Soltész, \& Bodacz-Nagy, 2014). This was partly due to the fact that, as a result of Citizenship Act in 2011, Hungarians living abroad had the opportunity to obtain Hungarian citizenship and arrive in the country as citizens rather than immigrants. The decline in the number of ethnic Hungarians was partly compensated by immigrants from the EU, half of whom were Germans (Gödri et al., 2014).

The question then arises as to why migration has been dominating public discourse in Hungary at a time when the number of immigrants entering the country has been on the decline, and the issue and implications of migration seem to have no novelty value in the Hungarian context. In order to be able to - partially - answer this, the following questions will be raised in the study:

1. What migration-related terms and in what senses and connotations are used in public discourse and how this particular kind of use may influence public perception of immigrants? 
2. How were immigrants and migration represented in the 2016 political campaign of the Hungarian Government and in the counter-campaign of the opposition TwoTailed Dog Party?

3. How does the theme of migration feature in Hungarian state education, and in the Hungarian National Core Curriculum in particular?

4. Does the teaching of English play a role in the discussion or handling of migrationrelated issues?

Since migration is a highly charged political issue in Hungary, there is a lack of research examining how migrants are portrayed in public discourse, including education, unlike elsewhere in Europe or the USA (see, for example, Catalano, 2016; Guido, 2012; Hart, 2010).

\section{Method}

The research comprises a case study of Hungary with regard to migration in the second half of the 2010s. The type of method that has been applied to answer the research questions is the analysis of documents and realia. The document sources include the Stop Soros legislative package proposal of the Hungarian Government (2012), the billboards of the 2016 campaign, the counter-campaign as well as the Hungarian National Core Curriculum (2012). The Stop Soros proposal serves the purpose of exploring the use of migration-related terminology, while the billboards provide data about the representation of migrants and migration in the Hungarian public discourse. The study of Hungarian National Core Curriculum aims to find out how migration features in the official guidelines for Hungarian state education.

The investigation of the data is based on critical discourse analysis (CDA), which views language and discourse as social practice: "[d]escribing discourse as social practice implies a dialectal relationship between a particular discursive event and the situation(s), institution(s) and social structure(s), which frame it: The discursive event is shaped by them, but it also shapes them" (Fairclough \& Wodak, 1997, p. 258).

The text analysis of the documents intends to shed light on how various discursive mechanisms and strategies are exploited in the realisation of the Hungarian government's political stance with regard to migration. In so doing, the text analysis draws on the Discourse-Historical Approach (DHA) which enables the researcher to identify the topics as well as the discursive strategies that have been used in the case of a particular discursive event. The strategies that pertain to the analysis of the Hungarian documents and billboards include intensification, nomination, i.e., how social actors or phenomena are referred to linguistically, and predication which identifies the characteristics and qualities assigned to social actors or phenomena (Reisigl \& Wodak, 2009). The investigation of the portrayal of migration and migrants in Hungarian political discourse also draws on the particular social practices employed in the representation of migrants (van Leeuwen, 2008). The relevant practices include impersonalisation, a type of objectivation, and individualisation. Since the sources in this study contain billboards, categories (e.g., communicating 
social distance and social relations in pictures) suggested by van Leeuwen (2008) for the analysis of the visual representation of social actors feature in the present research as well.

\section{Analysis of billboards and documents}

\subsection{Stop Soros legislative package proposal}

\subsubsection{Findings}

The purpose of the Stop Soros proposal is to force organisations which promote "mass migration" (p. 2) and are funded by international organisations to register and pay duties. In addition to organisations, there are sanctions against persons "organising immigration" (p. 2) who are either compelled to stay away from the borders or are refused access to such areas.

The title of the proposal refers to George Soros, a Hungarian-born billionaire and philanthropist, who is the founder of the Central European University and the Open Society Foundations. He is a well-known advocate of democracy and human rights. $\mathrm{He}$ supported the opposition before and during the collapse of communism in Hungary and elsewhere in Eastern Europe. Among the beneficiaries of Soros grants was the current Prime Minister of Hungary (https://www.kas.de/c/document_library/get_file?uuid=5d607048-a3d3-8ed7-93bd23c2ae9d71de\&groupId=252038). Recently, Soros has been the target of severe criticism for his alleged plan to resettle millions of illegal immigrants in Europe and financing civil movements which assist migrants, including refugees in Hungary.

Since the proposal of the Stop Soros legislative package represents a legal text which, by its very nature has to be in pursuit of precision (Gibbons, 2003), the document can be expected to provide a consistent and clear use of migration-related terminology. The aim of the analysis of the proposal is, therefore, to examine the terms that are used to refer to "refugees, asylum seekers and immigrants" (KhosraviNik, 2010, p. 1) who arrive at the borders of Hungary.

There is an array of various terms used already at the beginning of the document. In the second paragraph of the introduction (p. 2), there is reference to "immigration" and "immigrants". The subsequent paragraph qualifies immigration as "illegal" and includes the collocations of "immigration pressure", "migration propaganda", "human traffickers" and "illegal border-crossers who deserve a better life". The confusion and blurring of the distinction between different types of migration continues on the same page. The text claims that the proposed legislation is aimed at identifying "organisations supporting migration" and that Hungarians demand a "strong action against illegal immigration" and promote the strengthening of the protection of borders instead of "resettling" migrants.

The legislative package then raises the issue of the social responsibility of "organisations supporting illegal migration". Interestingly, within the same section (p. 3) the expression "organisations supporting migration" is also used. The terminology 
changes on page 4, where there is reference to "illegal migrants" twice. However, from this onwards, the expression "organisations supporting illegal migration" becomes the most frequently used and standard terminology in the document: on pages 5-7, it occurs 16 times. Towards the end of the document (p. 17), the terms "organisations supporting illegal migration" and "organisations supporting migration", without the "illegal" qualifier are again used interchangeably: the former twice, while the latter four times.

The notion of an organisation supporting illegal migration is defined as an organisation or fund registered in Hungary which sponsors the illegal entry, takeover and stay of a third-country national applying for international protection in the EU, and which receives funding directly or indirectly from abroad (p. 5). There are at least two contradictions here. One is the paradox of how an organisation engaging in illegal activity can be recognised as a legal entity once it has been registered as an "organisation supporting illegal immigration". The second is the question of how the sources of funding pertain to the definition of such an organisation. The definition also seems to imply that organisations involved in the support of illegal migration are exempt from the payment of duties if they receive financial support from Hungarian sources. An organisation can thus have charitable status and be exempt from the payment of duties if it "has sufficient resources to meet the shared needs of society and the individual" and "can demonstrate that it has sufficient public support" (p. 14). Public support here means that at least half of the funding the organisation receives is from sources which are either resident or registered in Hungary and that the funding received from taxpayers' contribution to charitable organisations reaches at least half of the amount received from sources outside of Hungary (p. 14). It appears that the negative representation of particular organisations depends on the funding sources which, in turn, is an indicator of their public support.

\subsubsection{Discussion}

What transpires from the proposal is that migration-related terms are used in a cavalier manner, which is fairly unusual in legal documents (Gibbons, 2007). First of all, there is no clear distinction between migration and immigration. One of the consequences of this is that the slightly more positive representation of migration (as opposed to immigration) which can be found in British newspapers (KhosraviNik, 2010), for example, does not feature in the legislative package. Another implication is that since migration is equated with immigration and both have negative connotations, emigration does not constitute part of the concept of migration and is perceived a separate entity which does not carry the negative associations migration and immigration are given in the Hungarian context. So rather than functioning as a superordinate with immigration and emigration as its hyponyms (Figure 1a), in this document migration is a synonym of immigration and represents the same level of abstraction as immigration and emigration (Figure 1b).

Migration 


$$
\text { Immigration Emigration }
$$

Figure 1a. Semantics of migration terminology

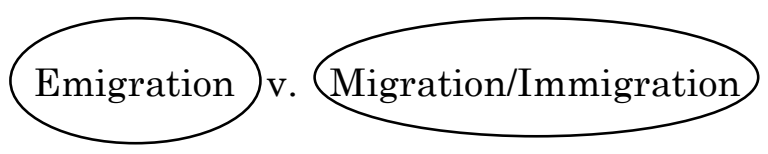

Figure 1b. Migration terminology in the legislative package

Moreover, both migration and immigration are used more frequently with the "illegal" qualifier than without, which gives the impression that all cases of migration and immigration are against the law. This reflects the use of predication strategies (Reisigl \& Wodak, 2012), whereby the most characteristic feature assigned to (im)migration in this document is the fact that it is "illegal" and as such poses a problem (van Leeuwen, 2008). The negative perception of (im)migration is reflected in other collocations as well. Apart from combining with the adjective "illegal", expressions in the document include "immigration pressure", "mass immigration", "crisis situation caused by immigration", "crisis situation caused by mass immigration" and "action against illegal immigration".

The collocations and other references evidence that the main topoi of the document are the topos of threat (KhosraviNik, 2010) and the topos of damage. Immigration presents a threat to national security (p. 2 ; p. 20; p. 23) endangering public interests, public safety, public order as well as public health (p. 20). Organisations supporting "illegal immigration" also pose a threat to the present constitution of the Hungarian population by, among others, intending to derail the government's immigration policy and cause damage to the national budget.

Throughout the document, those arriving at Hungary's borders are impersonalised (van Leeuwen, 2008) and are represented by abstract nouns rather than as persons. Immigrants are thus dehumanised (KhosraviNik, 2010). In the document, the noun "immigrants" appears once and "migrants" twice, whereas the abstract notion of immigration 25 times, often with negative qualifiers, such as "mass" or "illegal".

Furthermore, the different types of immigrants are not distinguished either. There is no reference to refugees or asylum seekers and their plight, nor is there a positive view of the support organisations may give to them. The main form of identification for all immigrants is negative in that they are classified as illegal (van Leeuwen, 2008). The only instance of individualisation (van Leeuwen, 2008) is the single mention of immigrants deserving a better life (p. 2). Otherwise, the human side of migration does not feature in the legislative package at all. The word refugee is mentioned only three times, once in the reference to the protection of borders against migrants and twice in the Hungarian title of the Minister for Immigration and Asylum. 
In sum, the document conflates various migration-related issues, resulting in an imprecise and confusing use of the relevant terms. It also represents people involved in and with migration in an impersonalised manner as abstractions. The dominant representation of migration in the document is negative and the main message is that migration poses a serious threat to the Hungarian nation.

\subsection{Billboards}

\subsubsection{Government campaign}

In its campaign for the referendum against the forced resettlement of migrants in 2016, the Hungarian government used billboards to disseminate its view on the matter. The exploitation of billboards for political purposes is not new. However, what was different in the Hungarian context is that it was the government which put up billboards all over the country to convey its anti-immigration message.

While in Britain, for instance, the platform of anti-immigration discourse is mainly the print and online news media (Hart, 2010), in Hungary the genre of billboards has proved to be highly effective in communicating the government's ideology for several reasons. First of all, unlike print, online or other types of media, billboards provide a free and highly accessible display place for the public, and thus have greater distributional power than newspapers or television which require subscription. In a similar vein, whereas journalism entails secondary texts which "act as a lens through which primary texts are reified but may also be recontextualised" (Hart, 2010, p. 17), billboards comprise primary texts emanating directly from the source with no intermediary commenting on them. Third, messages on billboards are brief and limited to the very essence of the message, demanding very little processing effort on the part of the reader. Fourth, the Hungarian government's billboards demonstrate the kind of cooperation which is characteristic of communication for manipulation:

Text-producers would just not have been prepared to share valuable information unless, through reciprocal altruism, it served some long-term interest. And potential text-consumers would simply have refused to listen to and comprehend language if it went against their short-term interests. (Hart, 2010, p. 42)

In the Hungarian context the long-term interest of the government (generate fear of a group of people against whom the government can protect the country) coincides with how some of the population view immigrants. In a survey on Hungarians' attitude towards refugees between 1992 and 2012, it was found that a considerable section of society is xenophobe (40\% in 2012), with xenophiles reaching only around $10 \%$ on average (Gödri et al., 2014). Interestingly, from the mid-2000s, the survey questions about providing asylum in Hungary included a made-up ethnicity, the Piresians, whose rejection indicated the "the overall, unspecified xenophobia of the respondent (59 per cent when first asked in 2006)" (Gödri et al., 2014, p. 18).

In what follows the messages and the delivery of the Hungarian Government's ideology on the billboards will be examined (Appendices A-G). 


\subsubsection{Analysis}

The background of the billboards is always the same hue of blue which makes them distinguishable straightaway. The messages on the billboards (see Appendices A-C) name and shame the person or the organisations which allegedly intend to force Hungary to accept immigrants against its will. All three contain a statement, the validity and truth of which are fortified by different rhetorical devices. The first one (Appendix A) uses multimodality, in the road sign STOP complemented with the name of George Soros, the Hungarian-born billionaire who has been unfoundedly accused of masterminding the resettlement of millions from Africa and the Middle East. Although the visual renders a strong and straightforward message, the text itself is less direct in its wording. For example, the agent performing the act of stopping Soros remains hidden. Is it the reader, the government or both together who should grapple with the task? The readers must work it out for themselves and in so doing they engage with the text, thus fulfilling the purpose of the political campaign. Also, rather than naming the people Soros intends to resettle in Hungary, a metonym is used where the regions stand for the people who come from those particular parts of the world.

In Appendix B, it is the EU that is accused of wanting to resettle thousands of illegal immigrants in Hungary. Here, too, a metonym is used (location for organisation), which makes the EU more alien by emphasising the geographical distance rather than showing Hungary as one of the EU member states. The text exploits the discursive strategy of intensification (Reisigl \& Wodak, 2001) by asking a question (Did you know?) instead of using an assertion. The billboard in Appendix C refers to the UN's migration policy and implies that it is the UN, of which Hungary is also a member, which aims to force Hungarians to accept a policy that is alien to them. This time, the message is intensified by adding a sentence ending with an exclamation mark.

In Appendices D-E, it is mainly the visual representation of the social actors which helps emphasise the message. The picture in Appendix D depicts a smiling young woman as an individual representing Hungarians who reject illegal immigrants. She is shown in "close-up", which creates a short distance between the viewer and the image, and represents the person as if she is "one of us" (van Leeuwen, 2008, p. 138). Furthermore, the young woman is face-to-face with the viewer which strengthens the involvement between the viewer and her. The frontal angle also suggests openness and honesty.

In contrast, the imagine of the billboard in Appendix E could not be more different. The people there are depicted as a group, a stream of refugees who look similar. This homogenisation and impersonalisation gives the impression that "they're all the same" and "you can't tell them apart" (van Leeuwen, 2008, p. 144). The perceptible distance between the viewer and the refugees is created with the use of a "long shot". 
The oblique angle and the high position of the viewer enable the viewer to look down on the people in the picture, thus further increasing the social distance between the immigrants and the intended audience of the image. The social distance also reflects the power relation between the social actors as "[t]o look down on someone is to exert imaginary symbolic power over that person" (van Leeuwen, 2008, p. 139). The picture of the crowd of immigrants and the reference to the continents where they may come from indicates that it is immigrants from particular cultures who are all considered as illegal and who are not welcome in Hungary.

The billboards in Appendices $\mathrm{F}$ and $\mathrm{G}$ contain directives and seemingly address immigrants rather than the Hungarian public. Both begin with the clause "If you come to Hungary" and tell immigrants to respect Hungarian culture and not to take Hungarians' jobs away. Interestingly, in both texts the informal ' $t u$ ' (French form for familiarity between speakers, Yule, 1996) is used instead of the polite ' $v u$ ' which would put the addresser and the addressee on an equal footing. Although the informal register usually indicates smaller distance between the interlocutors, in these two billboards the use of ' $t u$ ' creates a power relation whereby "the more powerful speaker will tend to use the ' $t u$ ' version to a lower, younger and less powerful addressee" (Yule, 1996, pp. 10-11), thus putting immigrants into an inferior position. The fact that the language of the text is Hungarian indicates that the intended audience is, in effect, the Hungarian public.

\subsubsection{Billboards: Resistance discourses}

Those who disagreed with the government's anti-migration campaigns responded in two ways: either damaged the billboards by tearing them off and painting over them or organised a counter-campaign by displaying billboards ridiculing the government's political discourse. The counter-campaign was organised by the joke political TwoTailed Dog Party and was financed through donations by members of the public. As a result, around 500 billboards were put up nationwide (Kiss, 2016). In what follows, the analysis of some of the billboards by the Two-Tailed Dog Party will be presented.

The billboards displayed by the Two-Tailed Dog Party usually had only a brief text on them, with the pictures limited to that of the party's logo - a two-tailed dog. The layout and the colour were often the same as those of the official campaign. Whereas at the top the government billboards had "Government information" written, the TwoTailed Dog Party put "MKKP \& Thick-skin blog information”, where MKKP stands for the acronym of the party in Hungarian. The name of the blog is similar in meaning to the English thick-skinned expression, except that the Hungarian idiom "to have a thick skin" usually refers to one's face, and carries the meaning that a person with such a skin can do nasty things without feeling remorse or guilt.

The billboard in Appendix $\mathrm{H}$ is a response to the one in Appendix $\mathrm{F}$ which warns immigrants against taking the jobs of Hungarians. The sentence on the counterbillboard presents a contradiction by juxtaposing two stereotypes: immigrants don't work and they take the locals' jobs away. Of the two stereotypes, the second one refers directly to the billboard in Appendix F. The contradiction makes the text ambiguous, 
and in so doing flouts Grice's (1975) maxim of manner. The implicature generated by the flout gives rise to additional meaning which, in this case, is probably the paradox of refusing entry to immigrants in a country where there is a labour shortage, partly caused by the emigration of Hungarians to other EU countries.

The billboard in Appendix I is the paraphrase of the one in Appendix G (If you come to Hungary, you must respect our culture). While the sentence structure is the same (if you ..... you must ......), the addressee in the counter-campaign is the Hungarian Prime Minister who is instructed to obey the laws of Hungary: If you are the Prime Minister of Hungary, you must observe our laws. As in the government campaign, the informal ' $t u$ ' is used in the address (Yule, 1996), putting the Prime Minister into an inferior position. Similarly to the government billboard, the identity of the speaker is blurred here, too. Both the government and the MKKP billboards use the first person plural where ' $w e$ ' seems to be inclusive of the people of Hungary in whose name the speakers make statements employing similar grammatical structures but with different meanings. Whereas in the case of the government billboard ' $w e$ ' includes the government and the people of Hungary, in the counter-campaign ' $w e$ ' refers to the Two-Tailed Dog Party, claiming representation of citizens, some of whom in fact provided the funding for the campaign using their own money.

The billboard in Appendix J, echoes the question of Did you know? of the government billboards, such as the one in Appendix B. In so doing, this text also exploits the discursive strategy of intensification (Reisigl \& Wodak, 2001) but provides information (An average Hungarian comes across more UFO's in the lifetime than immigrants) which borders the absurd and consequently flouts Grice's maxim of quality. The implicature thus generated highlights the unfoundedness of the government's claims regarding the mass arrival of migrants into the territory of Hungary.

So far, this study has focussed on political discourse about immigration in Hungary in relation to a legal document and two billboard campaigns. In what follows the question of whether the representation of migration in Hungarian state education provides a more balanced view is addressed. In order to answer this question, the Hungarian National Core Curriculum is examined with regard to references made to migration in the document.

\subsubsection{The National Core Curriculum (NCC)}

The NCC provides the framework for the local curricula and "specifies a) the theoretical, content-related and methodological basis of the pedagogical tasks of school education, b) the main fields and content of the subject areas to be taught" (NCC, 2012, p. 1) on all levels of primary and secondary education (from Grade 1 to Grade 12).

The NCC lays the primary emphasis on the importance of patriotism as well as on knowledge about Hungary and Hungarians, putting the knowledge of and concern with Europe and the world in second place: 
The NCC prioritizes knowledge about Hungary and its wider region the Carpathian Basin) - especially about the life of Hungarians living in the neighbouring countries - yet also lays emphasis on those content elements which underline that Hungary belongs to Europe. The NCC pays attention to global and comprehensive issues, emphasizing our shared responsibility for sustainability. (p. 8)

Learning about Hungary and its past begins in Grade 1 in Hungarian schools. For example, out of the ten topic areas to be covered in the first four years of primary school, six are linked to Hungarian culture and history. They include national festivals and symbols, legends, historical figures and famous Hungarians in the 19th and 20th century (pp. 84-85).

Migration receives less attention, and the word itself occurs six times in the document, mainly in relation to history. There are three mentions of migration with reference to early Hungarian and European history (p. 86). As for contemporary issues, migration features in the discussion of population and demography for 9-12 graders (p. 85) and in geography within the topic of the organisation and operation of world economy (p. 153), where workforce migration is mentioned as one aspect of social and economic mobility. Emigration appears in one instance, in connection with the teaching of "the literature of the Carpathian Basin and the emigration" (p. 45). However, there is no mention of immigration or refugees in the document. On the whole, migration in the NCC is treated either as a historical fact or as a global issue which makes migration distant from the students' immediate reality both in time and place. Such an approach then does not officially provide an opportunity for the students to engage individually and address current migration-related questions, including the paradox of the ubiquity of migrant discourse and the absence of immigrants in the country.

Apart from school subjects such as ethics, in the NCC it is the teaching of foreign languages where intercultural understanding and the appreciation of cultural diversity are among the skills to be developed (p. 21). The aim of foreign language teaching is for students to acquire "the general knowledge of the target language and intercultural competence: students must be able to interpret the differences between and similarities of their own culture and other cultures, and become more open and sensitive to other cultures" (p. 48). The reason for including culture in the curriculum is that "[l] anguage cannot be separated from the culture where it has evolved and exists" (p. 49) and, therefore, it is important that students familiarise themselves with the target culture and develop intercultural awareness.

In the NCC, the languages in public education are taught as foreign languages, with English being no exception. Teaching English as a foreign language, however, does not take into account the fact that nowadays English predominantly functions as a global lingua franca with non-native users constituting the majority of speakers (Graddol, 1997). This being the case, English cannot be linked up with any particular culture, which makes it different from other languages in language education 
(Seidlhofer, 2012). Focussing on one or two English-speaking cultures which are traditionally seen as relevant and targeting communication with their native speakers does not prepare learners for what they have to cope with outside of the classroom. In contrast, adopting an approach which promotes the teaching of English as a lingua franca could encourage Hungarian students to become competent speakers of the language in communication with a variety of English users, including those who flee to Hungary from war and persecution.

\section{Conclusions}

In the Hungarian political discourse, the notions of migration and immigration are conflated and are used interchangeably, and separately from emigration. In both the legislative package proposal and the government billboards under examination, (im)migration is seen as an illegal activity forced on Hungarians by George Soros, the EU or the United Nation. Migration is, therefore, perceived as a threat inflicted by impersonalised masses of (im)migrants who arrive from cultures which are very different from that of Hungary's. The result is an overall negative representation of (im)migration which is likely to evoke negative emotions, including fear and anxiety, among the Hungarian population. The billboards of the counter-campaign aim to allay that fear by making fun of the government's rhetoric.

The examination of the Hungarian National Core Curriculum shows that migration occupies a marginal position in the document, and is more of a historical issue than a problem of current concern. In addition, the NCC does not recognise the dominant function of English as a lingua franca and consequently fails to exploit the potential ELF may have for the development of tolerance and interest in people who are different. The task of improving understanding about migration by showing the human side of it thus remains with the individual teachers.

\section{References}

Catalano, T. (2016). Talking about global migration: Implications for language teaching. Bristol: Multilingual Matters.

Fairclough, N., \& Wodak, R. (1997). Critical discourse analysis. In T. A. van Dijk (Ed.), Discourse and social interaction (pp. 258-284). London: Sage.

Gibbons, J. (2003). Forensic linguistics: An introduction to language in the legal system. Oxford, England: Blackwell Publishing.

Government of Hungary (2012). National Core Curriculum. Magyar Közlöny [Official Journal of Hungary] Retrieved from regi.ofi.hu/download.php?docID=5846

Gödri, I., Soltész, B., \& Bodacz-Nagy, B. (2014). Immigration or emigration country? Migration trends and their socio-economic background in Hungary: A longer-term historical perspective. Working Papers on Population, Family and Welfare, 19. Budapest: Hungarian Demographic Research Institute.

Graddol, D. (1997). The future of English? London: The British Council.

Grice, P. (1975). Logic and conversation. In P. Cole and J. Morgan (Eds.), Syntax and semantics 3: Speech acts (pp. 41-58). New York: Academic Press. 
Guido, M. G. (2012). ELF authentication and accommodation strategies in crosscultural immigration encounters. Journal of English as a Lingua Franca, 1(1-2), 219-240.

Magyarország kormányának javaslata a Stop Soros törvénycsomagról [The Hungarian government's proposal on the Stop Soros legislative package] (2018) Retrieved from http://www.kormany.hu/download/c/9a/41000/STOP\%20SOROS\%20T\%C3\%96RV\%C3\%89N YCSOMAG.pdf

Hart, C. (2010). Critical discourse analysis and cognitive science: New perspectives on immigration discourse. Basingstoke, UK: Palgrave Macmillan.

International Organization for Migration (n.d.). Migration issues in Hungary. Retrieved from http://www.iom.hu/migration-issues-hungary

KhosraviNik, M. (2010). The representation of refugees, asylum seekers and immigrants in British newspapers: A critical discourse analysis. Journal of Language and Politics, 9(1), 1 28.

Kiss, E. (2016). "The Hungarians have decided: They do not want illegal migrants": Media representation of the Hungarian governmental anti-immigration campaign. Acta Humana, 2016(6), 45-77.

KSH Hungarian Central Statistical Office (n.d.) Population and vital events. Retrieved from http://www.ksh.hu/stadat_annual_1.

Reisigl, M., \& Wodak, R. (2009). The discourse-historical approach (DHA). In R. Wodak \& M. Meyer (Eds.), Methods of critical discourse analysis (2nd ed.) (pp. 87-121). London: Sage.

Seidlhofer, B. (2012). The challenge of English as a lingua franca. Anglistik: International Journal of English Studies, 23(1), 73-86.

van Leeuwen, T. (2008). Discourse and practice: New tools for critical discourse analysis. Oxford: Oxford University Press.

Yule, G. (1996). Pragmatics. Oxford: Oxford University Press.

\section{Appendix A.}

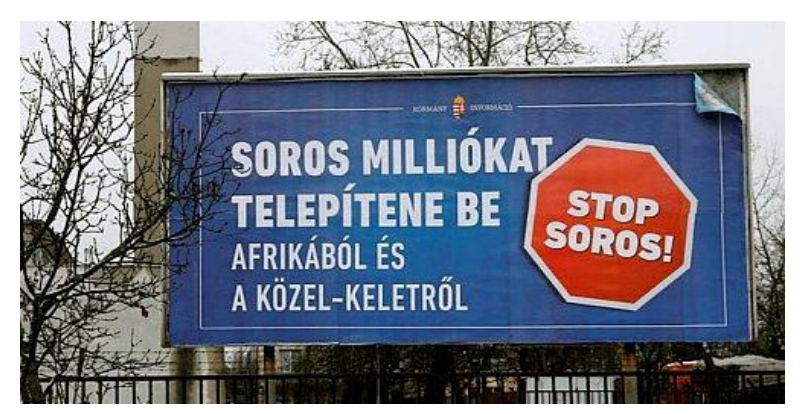

Soros would like to resettle millions from Africa and the Middle East

\section{Appendix B.}

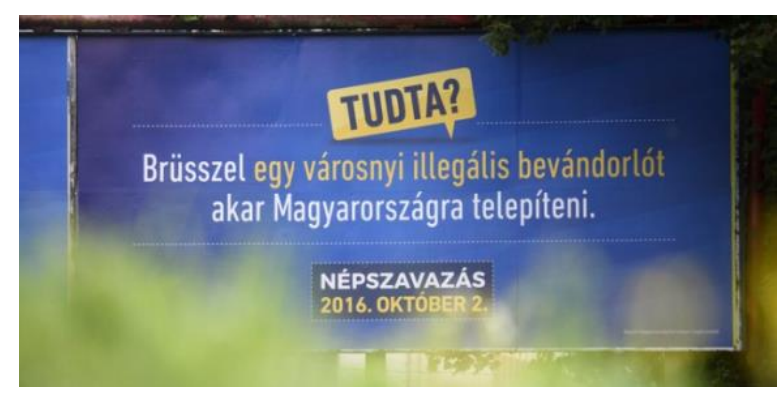


Did you know? Brussels wants to resettle so many illegal immigrants that could fill a town in Hungary.

\section{Appendix C.}

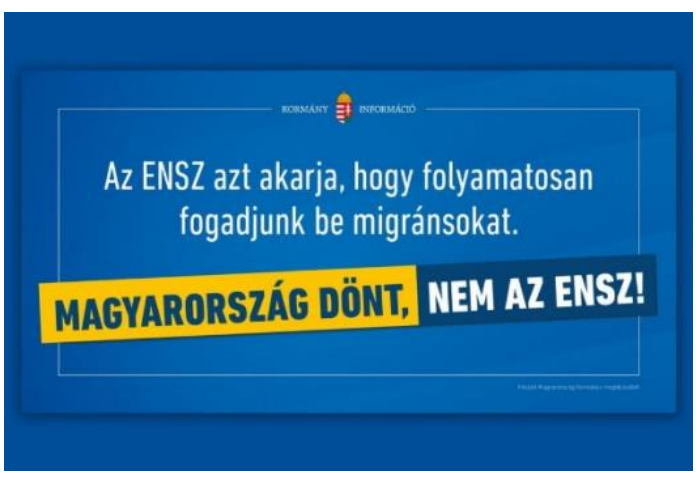

The UN wants us to continually accept migrants.

Hungary decides, not the UN!

\section{Appendix D.}

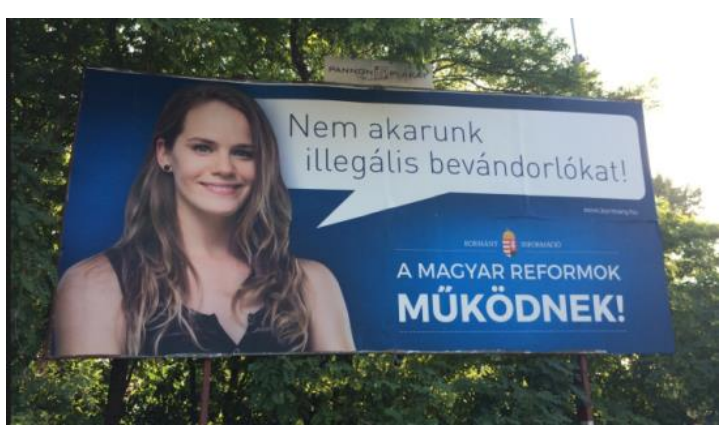

We don't want illegal immigrants! The Hungarian reforms work!

\section{Appendix E.}

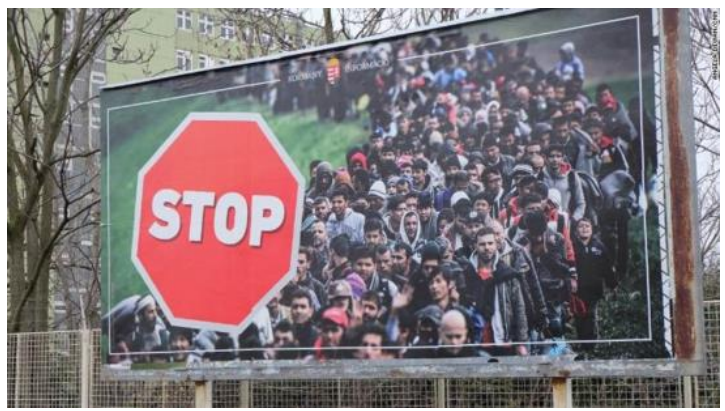




\section{Appendix F.}

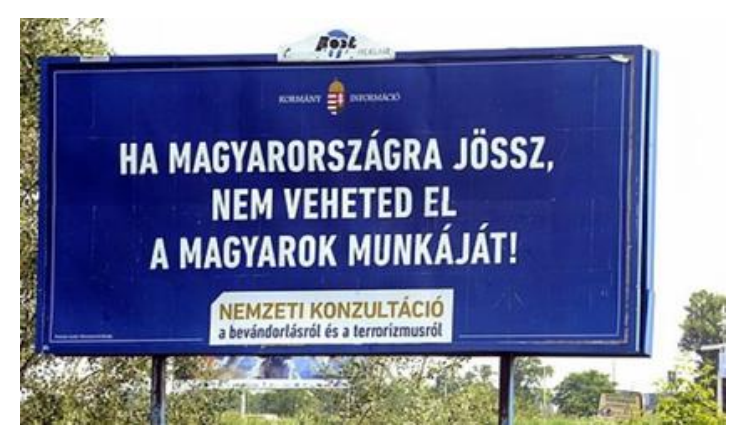

If you come to Hungary, you mustn't take away Hungarians' jobs!

\section{Appendix G.}

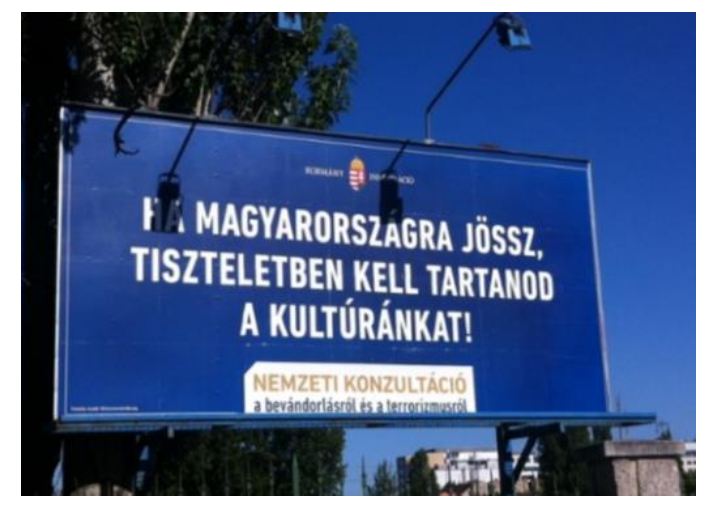

If you come to Hungary, you must respect our culture!

\section{Appendix H.}

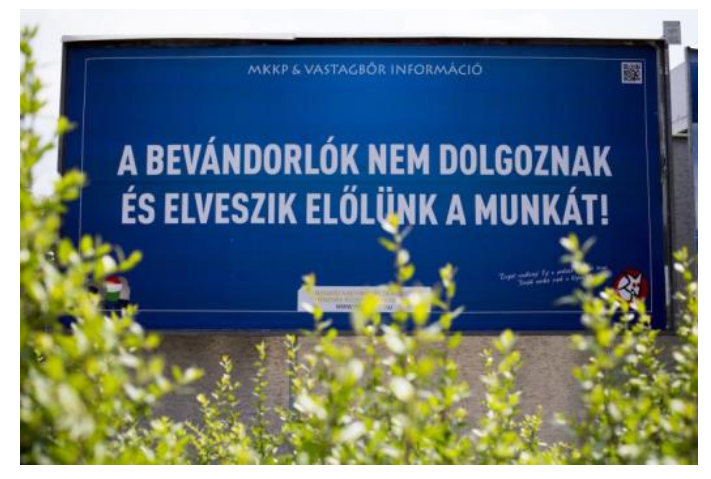

Immigrants don't work and take our jobs 


\section{Appendix I.}

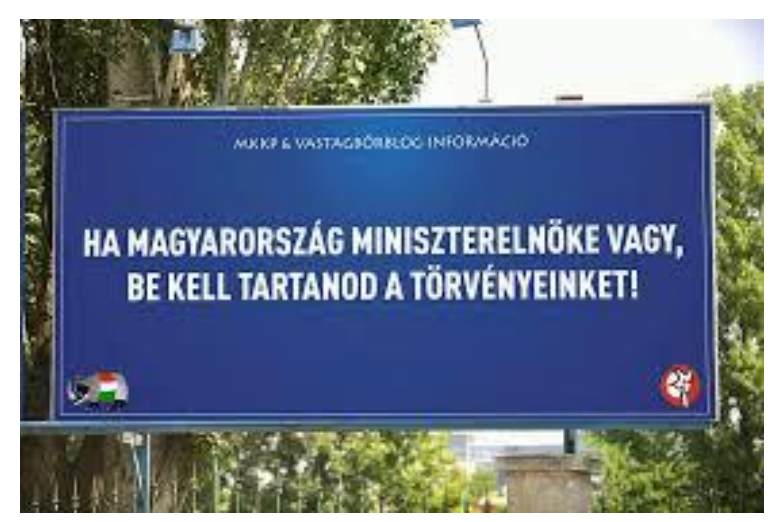

If you are the Prime Minister of Hungary, you must observe our laws.

\section{Appendix J.}

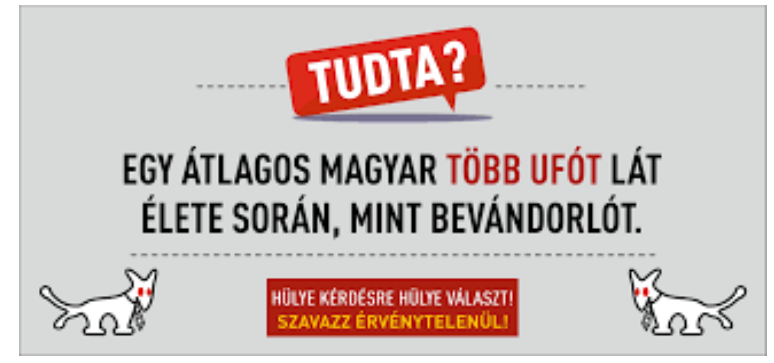

Did you know? An average Hungarian comes across more UFOs in their lifetime than immigrants.

In red: Stupid answer to a stupid question! Spoil your vote!

\section{Copyrights}

Copyright for this article is retained by the author(s), with first publication rights granted to the Journal. This is an open-access article distributed under the terms and conditions of the Creative Commons Attribution license (CC BY-NC-ND) (http://creativecommons.org/licenses/by-nc-nd/4.0/). 